\title{
El sistema financiero peruano: 1970-2004
}

$\mathrm{D}$ e 1970 a 2004 Perú transitó por tres etapas de su historia económica reciente. Entre 1970 y 1978 vivió los últimos años de una tardía experiencia de desarrollo basada en la industrialización sustitutiva de importaciones (ISI); éstos fueron seguidos de la larga crisis de este modelo de desarrollo, durante la cual el país experimentó a lo largo de sucesivos gobiernos una amplia gama de programas de estabilización fallidos, sin alcanzar a reformular un esquema de desarrollo que resulte viable. Las consecuencias más notorias de estos fracasos fueron, en el plano económico, el largo estancamiento asociado a un progresivo descontrol del proceso inflacionario, que culminó (19881989) en hiperinflación, y, en el plano político, en la pérdida de poder del Estado y la extensión a gran parte del territorio nacional de la violencia armada.

En 1990 se abrió un nuevo período: llegó la estabilización económica al país y el Estado recobró el control del territorio; se abandonó el modelo de desarrollo por la isi, lo que abrió la economía y regresó un esquema basado en la explotación de las ventajas comparativas de Perú en términos de riquezas naturales, en especial minerales.

En este marco general, ${ }^{1}$ ¿cuál ha sido la trayectoria del sistema financiero? Esta pregunta se intentará contestar en el presente artículo. La literatura subraya los efectos negativos de la represión financiera y de la inflación elevada sobre el desarrollo del sistema financiero. Si nos referimos a las políticas monetarias y financieras, el sistema peruano ha vivido dos etapas netamente diferenciadas. La primera, que cubre el período 1970-1990, es de represión financiera severa a aguda, y

\footnotetext{
* Profesora investigadora del Departamento de Estudios del Pacífico, de la Universidad de Guadalajara, e investigadora del SNI.
}

se caracteriza —a partir de $1975-$, por una pérdida de profundidad del sistema financiero. La segunda, que se inicia en 1990 y sigue hasta la fecha, se caracteriza por políticas neoliberales; éstas permitieron una recuperación inicial del sistema financiero, basada mayormente en la banca comercial, seguida de una incipiente diversificación que requirió de ciertas intervenciones públicas enfocadas a determinados segmentos del sistema. Estos temas serán desglosados en cuatro secciones. En la primera se presentan los antecedentes del sistema financiero peruano entre 1970 y 1990, mientras la segunda introduce las reformas aplicadas desde esta fecha. La tercera sección muestra los resultados alcanzados en términos de profundización y diversificación del sistema y la última analiza aspectos centrales de la problemática actual del sistema financiero peruano.

\section{Antecedentes: el sistema financiero peruano, 1960-1990}

Al inicio de la década de los sesenta, cuando Perú decidió abandonar su modelo histórico de desarrollo primario-exportador para adoptar un esquema basado en la industrialización sustitutiva de importaciones (IsI), el sistema financiero peruano era poco profundo y se centraba alrededor de la banca comercial y de diversas instituciones públicas de banca de desarrollo, que atendían sectores económicos específicos. El sistema bancario era regido por una añeja Ley de Bancos, emitida en 1931, que definía una organización bancaria de corte especializado.

Los primeros años del modelo de ISI se caracterizaron por un crecimiento del sistema bancario que indujo un modesto pero real proceso de profundización financiera: medidos en relación con el producto interno bruto (PIB) del país, los activos de la banca comercial pasaron de $12.9 \%$ en 1961 a poco menos de $16 \%$ en 1966 - 
1967, mientras que el crédito al sector privado se elevaba de $15 \%$ a $17 \%$ en el mismo período. Esta expansión bancaria se dio en el marco de una amplia apertura al capital extranjero, que controlaba en 1968 alrededor de $62 \%$ del capital del sistema de banca comercial. ${ }^{2}$ La propiedad del capital del sistema sufrió un cambio mayor con la nacionalización de los intereses extranjeros decretada por el gobierno militar reformista del general Velasco (1968-1975). De hecho, en la esfera financiera interna, el gobierno llegó a controlar gran parte de la asignación de recursos, mediante la banca de fomento o los bancos comerciales con participación pública.

A lo largo del período que acabamos de esbozar, el sistema financiero fue sometido a un típico régimen de "represión financiera", que incluía entre otros aspectos la fijación de las tasas de interés por las autoridades, la aplicación de requisitos de encaje legal elevados y el crédito dirigido a sectores seleccionados. Este régimen se volvió muy desfavorable al crecimiento del sistema financiero con la aceleración inflacionaria que se inició en la segunda mitad de los años setenta, con la crisis del modelo de ISI. En particular, la coexistencia de tasas de interés nominales fijadas por las autoridades y de una inflación alta y variable produjo tasas de interés reales negativas que penalizaban fuertemente a los depositantes.

En 1980, con la llegada al poder del gobierno civil de corte liberal del arquitecto Belaúnde, se tomaron algunas medidas que buscaban relajar la represión financiera, reduciéndose los requisitos de encaje legal (de 76\% a 15\%), y autorizándose la creación de certificados bancarios denominados en dólares de Estados Unidos. En un contexto de elevada inflación, devaluaciones abruptas y rendimientos reales muy negativos de los depósitos en moneda nacional, estos instrumentos se transformaron en vehículos privilegiados para la conservación del poder adquisitivo y llegaron a constituir, a inicios de 1985 , prácticamente $60 \%$ de la liquidez del sistema bancario. ${ }^{3} \mathrm{Si}-$ multáneamente, empezó a desarrollarse un activo mercado cambiario informal.

Un cambio abrupto en la política financiera se dio en 1985, pues en el marco de su programa de corte heterodoxo, el gobierno que entró en funciones ese año inauguró un nuevo período de represión financiera aguda para el sistema bancario. Decretó en particular la conversión en moneda local de los depósitos denominados en moneda extranjera, que produjo la desdolarización forzosa del sistema bancario, y el congelamiento de parte de estos depósitos.

Asimismo, se creó una nueva unidad monetaria, el inti, equivalente a 1000 antiguos soles.

El fracaso de las políticas implementadas se acompañó de un agudo deterioro de las relaciones con el sector privado y financiero en particular, que culminó en 1987-1988, cuando el gobierno declaró su intención de nacionalizar la banca comercial privada, una medida que no prosperó debido a la oposición que suscitó, pero que dio lugar a la creación de un sistema financiero paralelo.

La inflación alta que devino en 1988-1989 en hiperinflación contribuyó también a reducir a niveles mínimos la intermediación bancaria formal. La desconfianza del público aunada a la ausencia de instrumentos que permitieran proteger el poder adquisitivo, llevó simultáneamente a la dolarización extrabancaria del patrimonio financiero de las familias y al auge del mercado cambiario informal que invadió calles y plazas.

En 1989, antes del cambio de gobierno, tanto la liquidez del sistema como el crédito 


\section{Cuadro 1}

Perú: principales reformas financieras, 1990-2004

Medidas de alcance general

1990 Liberalización de precios y servicios. Introducción de un régimen de cambio flotante. Abolición de la obligación hecha a los exportadores de entregar sus divisas al banco central.

1991 Apertura de la cuenta de capitales; dolarización autorizada de la intermediación local. Inicia programa de privatizaciones de empresas públicas. Ley de inversión extranjera y establecimiento de garantías de estabilidad jurídica a los inversionistas.

1992 Nueva ley del banco central establece la preservación del valor de la moneda como objetivo central, elimina el financiamiento directo al sector público, el crédito selectivo y el establecimiento de tipos de cambio múltiple.

1993 Instauración de un sistema de fondos de pensiones privados.

1995-96 Acuerdos con la banca internacional en el marco del plan Brady y con los gobiernos acreedores reunidos en el Club de París.

2001-02 Política monetaria más expansiva, favoreciendo disminución y menor volatilidad de las tasas de interés en moneda nacional.

2003 Inicia política de mavor transparencia para fomentar una disminución de las tasas de interés activas.

Banca e intermediarios financieros no-bancarios (IFNB)

1990 Liberalización de facto de las tasas de interés (tasa máxima no reajustada a la baja en contexto de desinflación esperada).

1991 Nueva ley de instituciones financieras promueve el esquema de banca múltiple; se amplían facultades de supervisión de la Superintendencia de Banca y Seguros.

1990 Eliminación por etapas de la banca de fomento, subsistiendo una sola institución de segundo piso (Cofide)

1993 Reforma a la ley de bancos precisa el marco regulatorio y crea un sistema de protección de los depósitos; amplía las actividades de estos intermediarios, incluyendo arrendamiento financiero y fondos de inversión; autoriza la emisión de notas hipotecarias (bank issued mortgage notes). Se liberalizan plenamente las tasas de interés. Inicia privatización de la banca comercial.

1995 Establecimiento de agencias de calificación de crédito.

1996 Nueva reforma a la ley bancaria: fortalecimiento de la reglamentación, supervisión y adopción de los criterios de capitalización de Basilea. Se amplían las facultades de las compañías financieras y aseguradoras (incluyendo actividades de factoraje, titularización, operaciones con derivados).

1997- Fortalecimiento y modernización de la sbs.

$1998-$

2003 Intervención precautoria y cierre de bancos comerciales pequeños; reestructuración y absorción de dos bancos más grandes. Establecimiento de programas enfocados a evitar una crisis sistémica (swaps de bonos públicos contra cartera, inversión pública temporal en acciones de bancos).

\section{Mercados financieros}

1989 Creación de un mercado de dinero de corto plazo.

1991 Nueva Ley de Mercado de Valores moderniza instituciones e instrumentos.

1996 Nueva Ley de Mercado de Valores y Ley de Fondos de Inversión promueven la diversificación de instrumentos y la "democratización" de la inversión en valores, mediante la venta de participaciones públicas. Los bonos corporativos y cd se transan en un mercado OTC. Se autorizan ocho mercados de derivados de físicos e instrumentos financieros.

2002 Se inician emisiones regulares de títulos de deuda pública en soles, con el objetivo de ofrecer una curva de rendimientos de referencia de corto y mediano plazo que faciliten la emisión de títulos privados en moneda nacional.

Fuentes: Banco Central de Reserva del Perú, El costo del crédito en el Perú, disponible en línea en

http://www.bcrp.gob.pe/Espanol/Wpublicaciones/informes_especiales/D0172002-pdf. Óscar Dancourt, "Desafíos de la reactivación económica", Economía y sociedad, núm. 48, CIES, abril de 2003, consultado en http://consorcio.org/CIES/html/pdfs/bol48/Dancourt.pdf. Patricia Ledesma Liébana, "The Peruvian Experience with Financial Liberalization", ponencia presentada en el congreso de la Latin American Studies Association, Washington, DC, septiembre de 2001. Geneviève Marchini, "Un modelo macroeconómico de intermediación bancaria aplicado al caso del Perú, 1980-1990", ponencia presentada en el XI Encuentro Latinoamericano de la Sociedad Econométrica, 1992, El Colegio de México, México. Justine Newsome, "Andean banks tough it out", Euromoney, núm. 359, marzo, 1999, Londres, pp. 56-60. Jorge Rojas, "El influjo de capitales en el Perú: 1990-1998", Documento de trabajo núm. 177, 1999, Departamento de Economía, Pontificia Universidad Católica del Perú, Lima. 
interno habían caído a niveles dramáticamente bajos: $10 \%$ del PIB para la primera, $8 \%$ para el crédito interno y $6 \%$ para el crédito de la banca comercial. Frente a este debilitamiento extremo del sistema financiero formal, las nuevas autoridades que llegaron al poder en 1990 escogieron aplicar medidas drásticas.

\section{Las reformas desde 1990}

En efecto, las medidas aplicadas al sistema financiero a partir de 1990 se insertan en el marco más amplio del programa de choque introducido por el nuevo gobierno del ingeniero Fujimori. El cuadro 1 sintetiza las medidas más resaltantes que impulsaron la transformación del sistema financiero peruano. El inicio de la liberalización del sistema financiero interno se hizo en 1990-1991, a la vez que se introducía la rápida apertura de la cuenta de capitales. En el contexto de una pérdida de confianza generalizada del público hacia la moneda nacional, se autorizó asimismo la creación de depósitos y créditos bancarios en dólares (1991).

Las medidas relativas al sistema bancario comprendieron tres reformas de la ley de bancos. La primera significó la abolición de la antigua ley bancaria y la introducción de la figura legal de la banca múltiple. Una reforma adicional en 1993 amplió las facultades de los bancos, confirmó el retiro del Estado de las actividades bancarias, prohibiéndole la fijación de las tasas de interés, el establecimiento de directivas de crédito y la participación de largo plazo en el capital de entidades financieras, a la vez que precisaba la regulación del sistema.

La banca estatal de fomento se concentró en una sola entidad, la Corporación Financiera de Fomento (Cofide), a la cual se agregó posteriormente un Banco Agropecuario (Agrobanco); ambas instituciones realizan funciones de banca de segundo piso, otorgando líneas de crédito a otras entidades del sistema financiero. Finalmente, en 1996 se fortaleció una vez más la regulación y supervisión del sistema, y se determinó aplicar los criterios prudenciales de Basilea. Las crisis financieras internacionales (crisis asiática de 19971998 y las sucesivas crisis rusa, brasileña y argentina) tuvieron un fuerte impacto negativo sobre el sistema bancario peruano y justificaron una serie de reestructuraciones bancarias y la introducción de programas públicos de apoyo destinados a evitar una crisis bancaria de alcance sistémico.

Una serie de medidas de gran importancia buscaron profundizar el sistema financiero y diversificar el rango de instituciones financieras no-bancarias. En 1993 se creó un nuevo sistema de pensiones, basado en la capitalización individual, donde la gestión de los fondos de los ahorristas se halla a cargo de las Administradoras de Fondos de Pensiones privadas (AFP). Al igual que en los demás países que introdujeron este sistema, veremos que el ahorro forzoso así generado ha estimulado el mercado local de capitales. Cabe destacar igualmente la creación de una serie de instituciones microfinancieras, cuya importancia no radica tanto en su impacto macroeconómico inmediato como en su papel sobresaliente en materia de incorporación de nuevos segmentos de la población a maneras formales de ahorro y financiamiento. Las cajas municipales ( $\mathrm{CM}$ ), las cajas rurales de ahorro y crédito ( $\mathrm{CRAC}$ ) $\mathrm{y}$ las entidades de desarrollo a la pequeña y mediana empresa (EDPYME) surgieron a finales de la década de los noventa.

Por último, el mercado de valores fue objeto de dos reformas. La primera introdujo una nueva ley del mercado, que procuró modernizar su funcionamiento y autorizar nuevos instrumentos. Esta ley fue a su vez reformada en 1996 con el objetivo de ampliar la actividad de los mercados, y se crearon instrumentos adicionales.

\section{La evolución del sistema financiero peruano: principales indicadores}

En 2004 el sistema financiero supervisado por la Superintendencia de Banca, Seguros y las AFP comprendía catorce bancos múltiples, tres entidades bancarias estatales, cuyas activida- 
Cuadro 2

Perú: estructura del sistema financiero (2004)

\begin{tabular}{lccc}
\hline & Número de & \multicolumn{2}{c}{ Activos } \\
& empresas & Mill. de US $\$$ & Porcentaje \\
\hline Empresas bancarias & 14 & 19275 & 54.9 \\
Empresas financieras & 4 & 320 & 0.9 \\
Instituciones microfinancieras no-bancarias & 40 & 1197 & 3.4 \\
Cajas municipales (CM) & 14 & 884 & 2.5 \\
Cajas rurales de ahorro y crédito & 12 & 175 & 0.5 \\
Entidades de desarrollo a la PyME & 14 & 138 & 0.4 \\
Entidades estatales & 3 & 3744 & 10.7 \\
Banco de la nación & 1 & 2590 & 7.4 \\
Corporación Financiera de Desarrollo & 1 & 1119 & 3.2 \\
Banco Agropecuario & 1 & 35 & 0.1 \\
Empresas de arrendamiento financiero & 6 & 470 & 1.3 \\
Empresas de seguros & 12 & 2182 & 6.2 \\
Cartera administradoras de fondos de pensiones & 4 & 7899 & 22.5 \\
Otras & 29 & - & - \\
Total & 112 & 35087 & 100 \\
\hline
\end{tabular}

Fuente: Superintendencia de Bancos, Seguros y AFP, Boletín consolidado del sistema financiero al 31 de diciembre de 2004, http://www.sbs.gob.pe/estadistica/financiera/ 2004/Diciembre/SC0001-di2004.pdf.

des se limitan esencialmente a operaciones de segundo piso, 40 instituciones microfinancieras, doce aseguradoras y cuatro AFP. Con $55 \%$ de los activos, los bancos múltiples seguían constituyendo el principal actor del sistema, delante de las AFP, que acumularon en poco más de diez años de funcionamiento $22.5 \%$ de los activos del sistema, y $10.7 \%$ de los tres bancos públicos. Las empresas financieras y microfinancieras no-bancarias representaban menos de $5 \%$ de los activos totales (ver cuadro 2 ).
Si bien el sistema financiero peruano sigue siendo comparativamente pequeño, la recuperación posterior a la hiperinflación y el crecimiento que la siguió han sido relativamente rápidos, más no exentos de problemas. A lo largo de un período de cerca de 35 años (que inició en 1970), las razones de monetización y de crédito en relación con el PIB, ambos indicadores del proceso de profundización financiera, muestran como éste se interrumpe entre 1975 y 1978 , con el inicio de la larga crisis de la IsI. Tanto M2 como el crédito interno

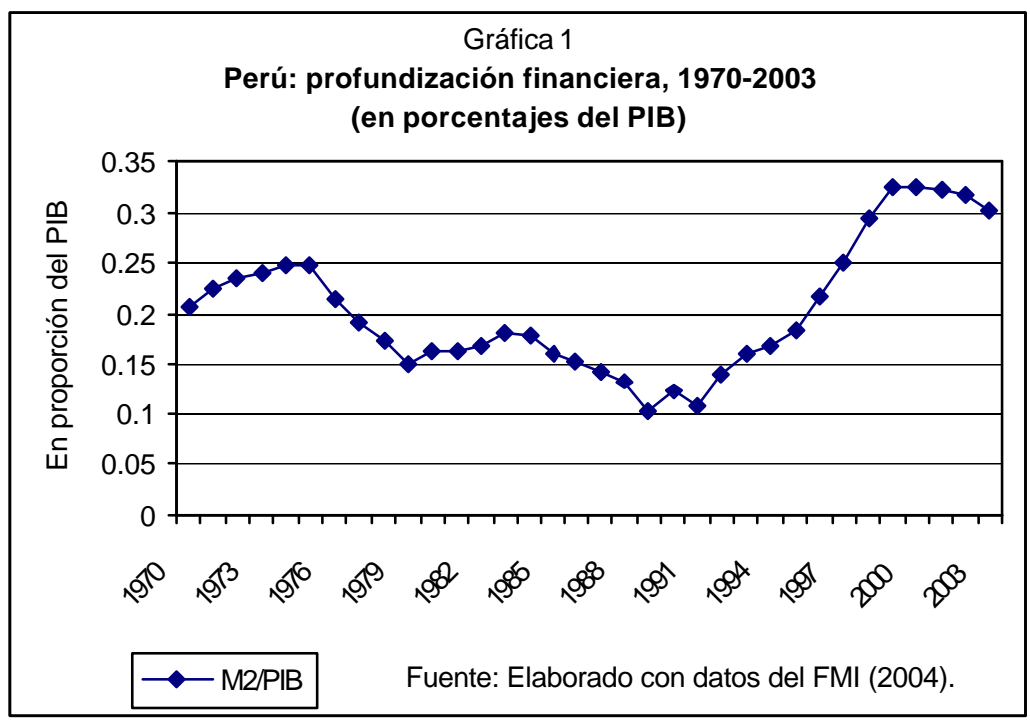




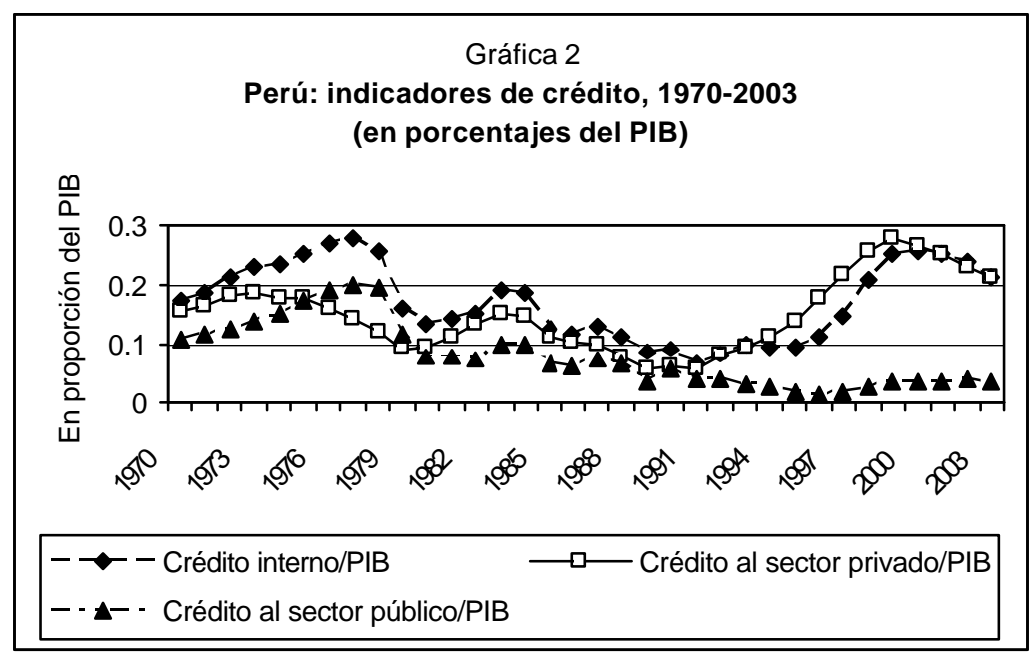

culminan en este lapso, el primero en 1975 en un nivel de $24.8 \%$ del PIB, mientras el crédito interno, impulsado por el crédito al sector público, lo hace en 1977 en $27.8 \%$ del PIB. Las recuperaciones posteriores de ambos indicadores fueron de corta duración, dándose un paulatino proceso de desintermediación y de "superficialización" financiera que se acelera a la par del alza de precios. Las reformas de la década de los noventa permitieron a Perú retomar un proceso de profundización financiera, el cual alcanzó un máximo en 1999, cuando los intermediarios bancarios se vieron atribulados por las consecuencias de las crisis financieras externas.

Ahora bien, el proceso que se inicia en 1990 presenta características novedosas que cabe resaltar aquí. En primer lugar, el crecimiento del crédito ha sido encabezado clara- mente por los préstamos al sector privado (gráfica 2), pues el crédito orientado al sector público, proporcionalmente importante en las dos décadas anteriores, se estableció en un bajo nivel después de 1990. En segundo lugar, el proceso se realizó bajo la iniciativa de la banca comercial: las otras instituciones financieras, que desempeñaban un papel importante debido a las intervenciones de la banca de fomento - alrededor de una tercera parte de los activos hasta 1989-, redujeron notoriamente su participación en los activos del sistema a partir de 1991, hasta representar menos del 5\% de los activos desde 1994 (gráfica 3).

En tercer lugar, esta expansión del sistema bancario se ha realizado en el contexto de una elevada dolarización: la proporción de la liquidez denominada en moneda extranjera alcanzaba $62 \%$ en 1992 , y se ha mantenido en

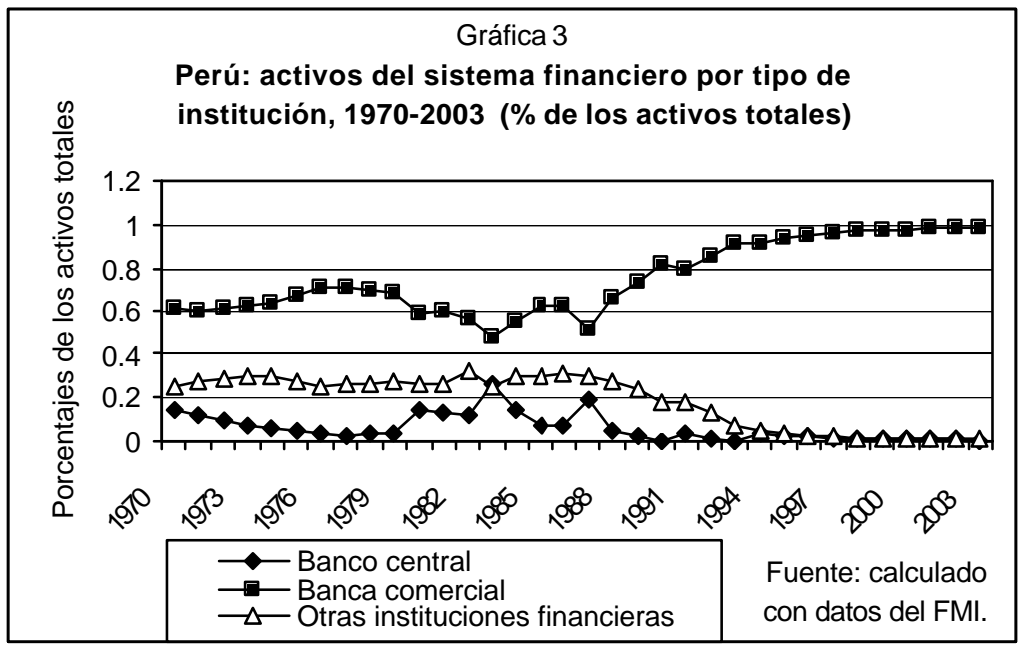




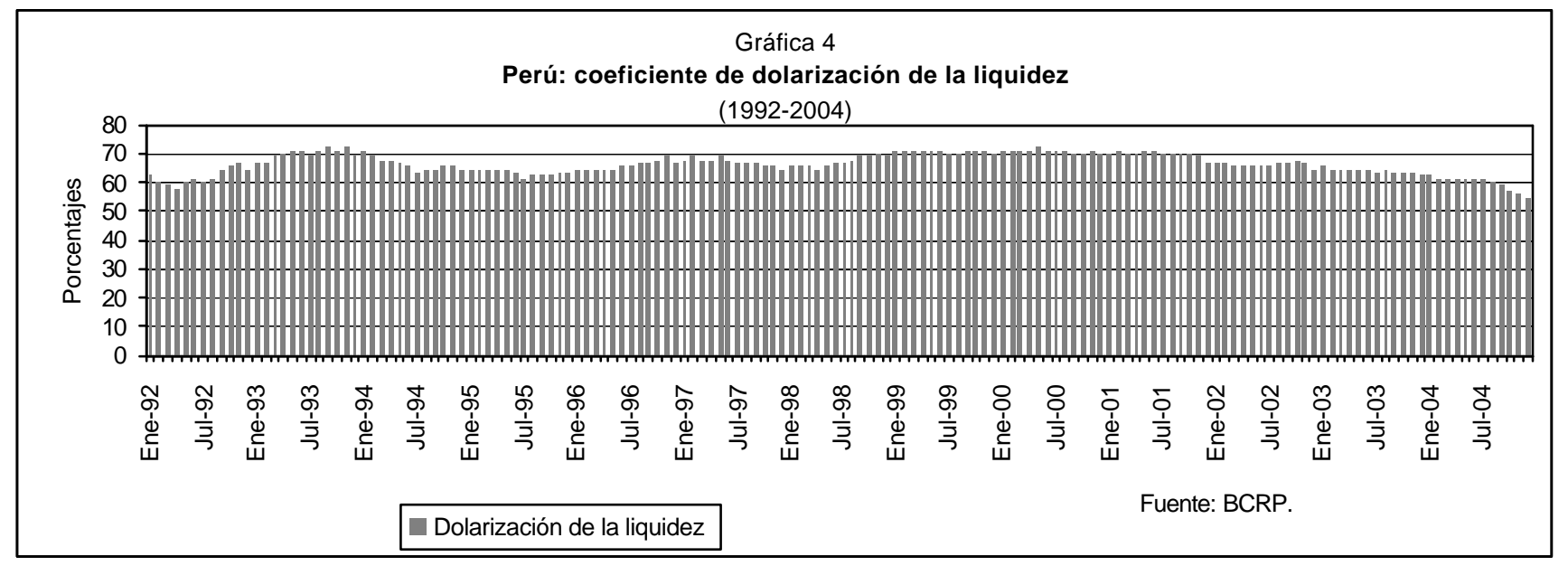

un rango variable pero muy elevado durante prácticamente todo el período, con "picos" que superaron el $70 \%$ en momentos de incertidumbre externa o interna. En la segunda mitad de 2004 esta proporción ha empezado a disminuir, pasando por debajo de la barra del $60 \%$ (gráfica 4).

La elevada dolarización de la liquidez del sistema tuvo como contraparte lógica una alta participación del crédito en divisas en el crédito total: de hecho la expansión crediticia registrada entre 1992 y 1999 se fundamentó en gran medida en el crédito en dólares, el cual alcanzó su nivel máximo en 1999 , con $22.5 \%$ del PIB, frente a préstamos en soles otorgados a altura de sólo $5.4 \%$ de este agregado (gráfica 5 ); en ese momento, $82 \%$ del crédito se concedía entonces en dólares.
En el período de auge económico y fuertes entradas de capitales del exterior (que va de 1992 a 1997), la proporción de crédito en dólares —superior a la dolarización de M2señala que los bancos peruanos recurrieron a préstamos internacionales para fondear los créditos concedidos en divisas a agentes locales. De hecho, la gráfica 6 indica que si la banca se ubica en tercera posición en cuanto a endeudamiento con el exterior, detrás del gobierno (84\% del total en $1990,69 \%$ en 2003$)$ y de las demás empresas privadas (respectivamente, $6 \%$ y $26 \%$ en las fechas señaladas), cuadruplicó sus pasivos externos con la banca internacional entre 1992 y 1997, cuando éstos llegaron a representar $14 \%$ del stock de este tipo de pasivos.

A partir de 1999 se dio un continuo proceso de disminución de los pasivos de la banca

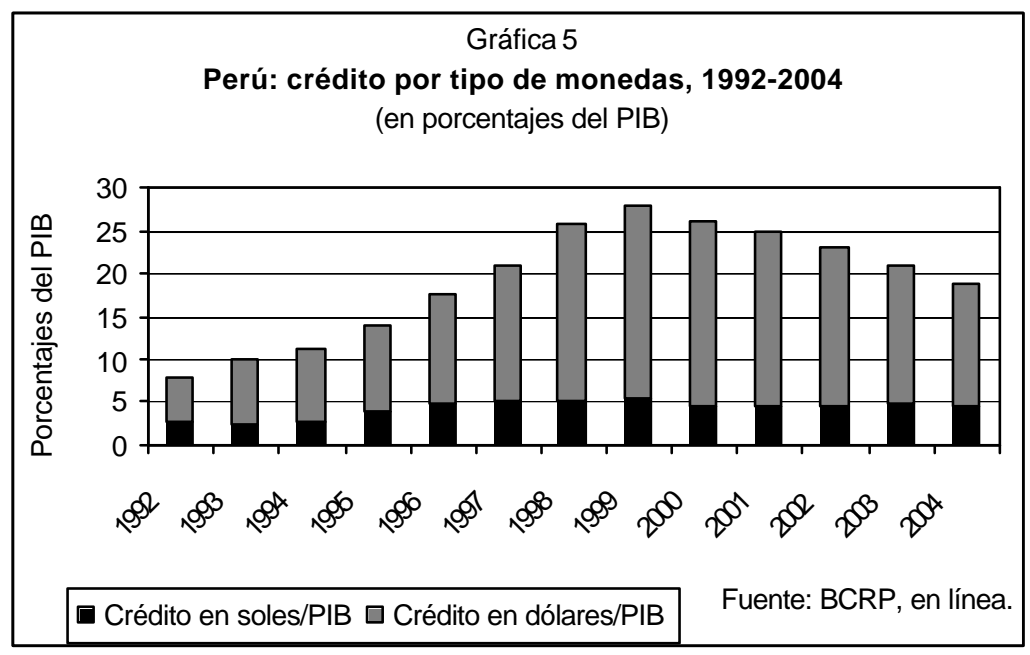




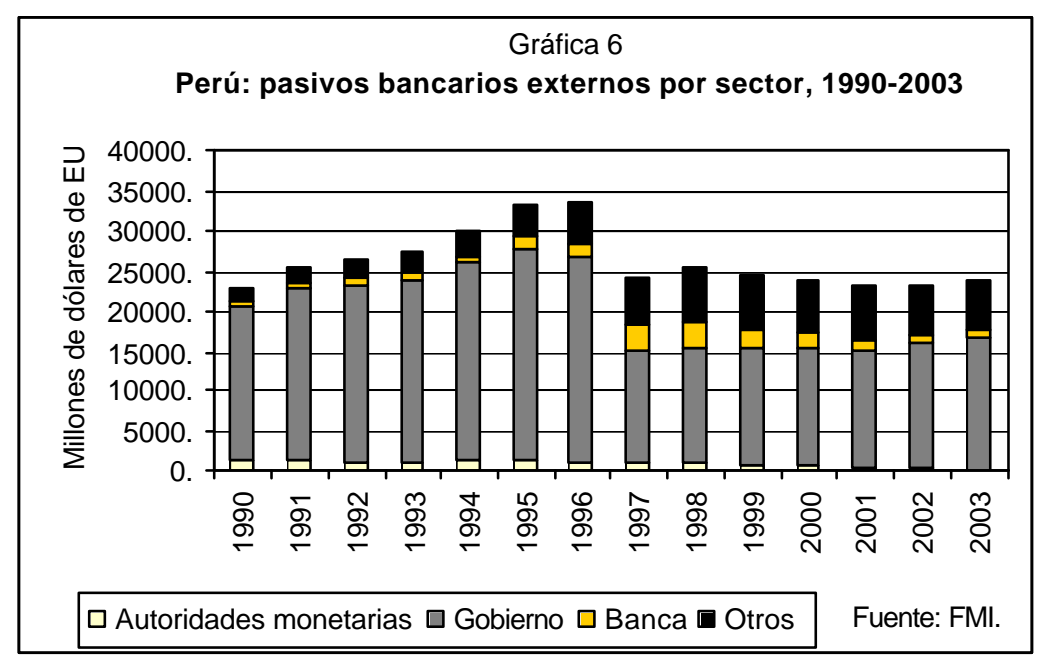

interna con el exterior, los cuales regresaron en 2003 al nivel promedio alcanzado en 19921993. Simultáneamente, el crédito concedido por estos intermediarios se contraía, como lo muestra la notable disminución del crédito en dólares, que no ha sido compensada por una insuficiente progresión del crédito en moneda nacional; el crédito bancario ha crecido con menor dinamismo que el PIB, y en 2003 el crédito en dólares se establecía en $14.2 \%$ de este agregado, mientras el crédito en moneda nacional seguía representando menos del 5\% (ver gráfica 5).

El comportamiento del crédito bancario a partir de 1999 constituye uno de los síntomas de la crisis y de la fuerte reestructuración que ha debido enfrentar el sector bajo el impacto de las crisis financieras externas y de sus efectos sobre una economía peruana vul- nerable y dolarizada, pero también como producto de la creciente competencia de los mercados de títulos negociables. El sistema bancario comercial había sufrido una primera reestructuración a principios de la década de los noventa. En 1991 y 1992 el sistema que comprendía 21 bancos, incluyendo la banca de fomento, experimentó cambios mayores. Se intervinieron, liquidaron o fusionaron seis bancos de fomento, liquidándose asimismo tres bancos de alcance nacional que contaban con una participación pública (Banco Comercial del Perú, Banco Popular y Banco de la Industria de la Construcción) y fusionándose cinco bancos regionales con los bancos Continental y del Libertador para conformar entidades de mayor tamaño. ${ }^{4}$ Entre 1994 y 1996 las privatizaciones bancarias llevaron a un cambio notable en la tenencia del capital de la banca, pues entraron con fuerza los inversionistas

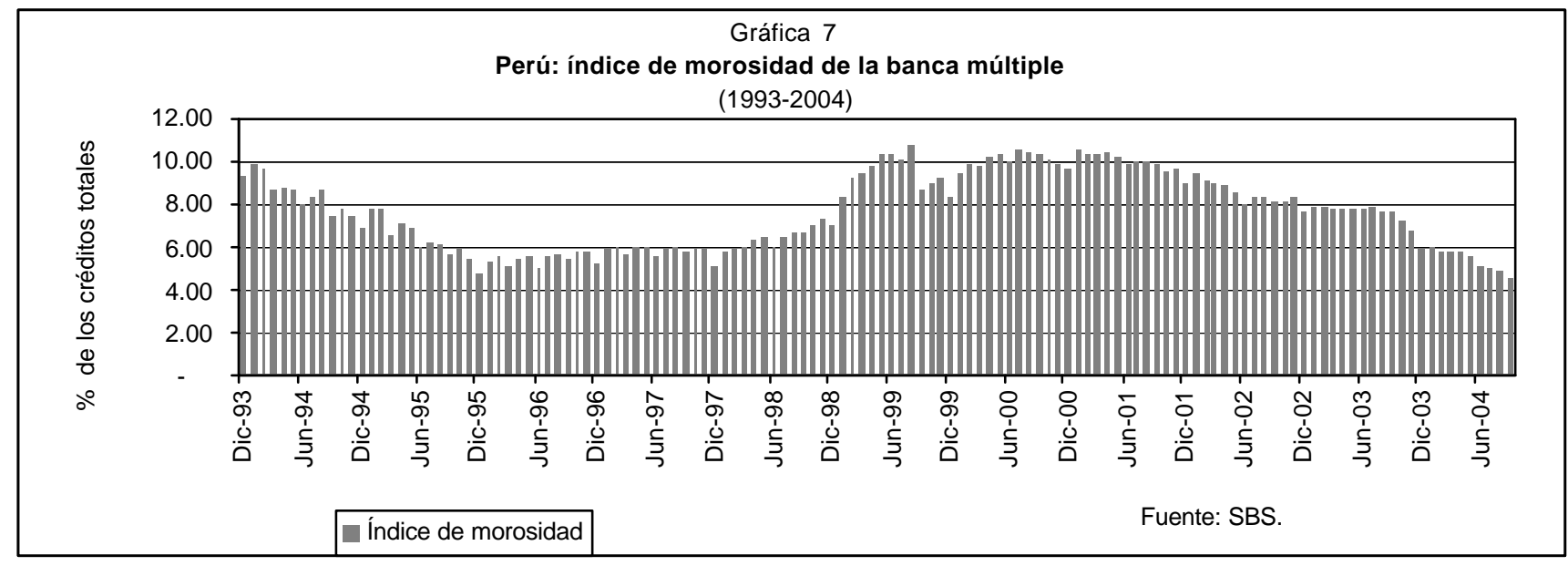


extranjeros: destacan las participaciones de capitales españoles, con la entrada de los bancos Santander y Bilbao Vizcaya, ${ }^{5}$ chilenos $^{6}$ e italianos. $^{7}$

Simultáneamente, entraban nuevos bancos con participación tanto local como extranjera, en especial chilena y estadounidense, al sistema. Al final de 1997 el sistema bancario contaba con 25 bancos, tres de los cuales eran de gran tamaño, los bancos de Crédito, Wiese y Continental, ocho medianos y catorce pequeños y dedicados exclusivamente al financiamiento del consumo. ${ }^{8}$ La crisis del sistema se puede apreciar en la gráfica 7: el índice de morosidad de la cartera bancaria, que había disminuido a menos de $6 \%$ del crédito total a finales de 1997, se eleva fuertemente y culmina en un nivel cercano a $11 \%$ de los préstamos totales en agosto de 1999, lo que generó entonces las condiciones para una segunda ronda de liquidaciones y fusiones, acompañadas de una creciente participación foránea.

Como resultado de las reestructuraciones implementadas, trece bancos dejaron de operar, sea que hayan sido liquidados, sea que hayan sido fusionados con otras instituciones; dos instituciones entraron al mercado, quedando en catorce el número de bancos en la actualidad. ${ }^{9}$ Las intervenciones elegidas por las autoridades peruanas incluyeron un trato diferenciado de los bancos, dependiendo de su tamaño. Los bancos chicos (República, Solventa, Bánex, Orión, Serbanco) fueron liquidados, mientras se buscó para los de mayor tamaño una salida diferente como la fusión-absorción, en general con participación extranjera. Así, el Banco Wiese, uno de los tres grandes en
1997, se fusionó con el Banco de LimaSudameris en septiembre de 1999, con aportación adicional de capital de este último. Además de las operaciones dirigidas a instituciones específicas, las autoridades aplicaron medidas de alcance más general, como los swaps de cartera de créditos por bonos del gobierno o participaciones temporales al capital, destinadas a fortalecer la salud financiera del sistema.

En el conjunto de operaciones involucradas en las dos rondas de reestructuración, el cambio en la composición de la propiedad fue de gran alcance, pues la participación pública pasó de 55\% de los activos bancarios en 1990 a $11 \%$ en 2002 , mientras la inversión extranjera directa se elevaba de $4 \%$ a 46\% (cuadro 3). En 2003 una operación de gran envergadura elevó notablemente el grado de control del capital extranjero, pues el mayor banco del sistema, el Banco de Crédito, fue absorbido por el banco español Santander Central Hispano.

Las reestructuraciones han tenido impactos profundos sobre el sistema bancario. En primer lugar, elevaron decididamente su grado de concentración. Así, la participación de los cuatro primeros bancos del sistema, que alcanzaba $53.9 \%$ de los préstamos brutos y $51.7 \%$ de los depósitos en 1990, se había elevado a $66 \%$ y $76 \%$, respectivamente, en $1999 .{ }^{10}$ En 2003 bastaban los tres primeros bancos del sistema para llegar a un resultado similar: $66.7 \%$ de los créditos y $74.8 \%$ de los depósitos. ${ }^{11}$ En segundo lugar, las transformaciones experimentadas por el sistema han contribuido a mejorar sus indicadores de salud finan-

Cuadro 3

Perú: estructura de la propiedad del sistema bancario, 2002*

\begin{tabular}{|c|c|c|c|c|c|}
\hline \multicolumn{3}{|c|}{1990} & \multicolumn{3}{|c|}{2002} \\
\hline \multicolumn{2}{|c|}{ Nacional } & \multirow[t]{2}{*}{ Extranjera } & \multicolumn{2}{|c|}{ Nacional } & \multirow[t]{2}{*}{ Extranjera } \\
\hline Privada & Pública & & Privada & Pública & \\
\hline 41 & 55 & 4 & 43 & 11 & 46 \\
\hline \multicolumn{6}{|c|}{ * En porcentajes de los activos bancarios totales. } \\
\hline \multicolumn{6}{|c|}{$\begin{array}{l}\text { Fuente: Committee on the Global Financial System, Foreign direct investment in the } \\
\text { financial sector of emerging market economies, marzo de 2004, Banco de Pagos } \\
\text { Internacionales, Basilea. }\end{array}$} \\
\hline
\end{tabular}


ciera. La menor dependencia de financiamiento externo y el papel preponderante de los depósitos como fuente de fondos (84\% del total en 2003) han reducido la volatilidad y el nivel de riesgo del fondeo bancario. ${ }^{12}$ La calidad de la cartera se ha elevado, con una disminución de los créditos en mora (ver gráfica 7), provisionados a altura de $141 \%$ en 2003, y una mayor proporción de créditos "normales", a la vez que las razones de solvencia y de liquidez se elevaban: las razones de capitalización se establecían en más de $13 \%$ en 2003 -el nivel mínimo es fijado en Perú a $9.1 \%$, un nivel superior a lo exigido por los criterios internacionales de capitalización de Basilea-y los ratios de liquidez superaban ampliamente los mínimos fijados en $8 \%$ para las operaciones en moneda nacional y $20 \%$ para las operaciones en divisas; la liquidez superaba $30 \%$ para las primeras y $40 \%$ para las segundas. ${ }^{13}$

Los primeros años de 2000 han sido marcados por la mayor competencia ejercida por los mercados de títulos negociables, la que ha llevado a un cambio, todavía en curso, en la composición de la clientela bancaria. Los bancos peruanos experimentan lo sucedido desde los ochenta en países de mayor nivel de desarrollo: parte de su clientela corporativa encuentra financiamiento en mejores condiciones al colocar sus títulos en los mercados locales, lo cual lleva a la banca a diversificar sus clientes, en particular hacia las familias, expandiendo su oferta de crédito hipotecario y de consumo, y hacia las PME y microempresas: el crédito comercial a empresas - que constituía $84.8 \%$ del total en 1999 , contra $6.9 \%, 7.1 \%$ y $1.2 \%$ respectivamente, para los créditos al consumo, hipotecarios y a la microempresa- había caído a $72.6 \%$ en 2003 , contra $11.6 \%, 12.8 \%$ y $2.9 \%$ para los demás destinos. ${ }^{14}$ Ahora bien, esta competencia del mercado de títulos no provino del mercado accionario sino del mercado de bonos.

En efecto, si bien el mercado accionario fue el primero en conocer un rápido crecimiento en los noventa, no constituye una fuente importante de financiamiento y el número de empresas que cotizan no se expande sensiblemente. Este mercado conoció una fuerte elevación del valor de sus títulos: de 1314 millones de soles en enero de 1992 a cerca de 52000 millones en junio de 1997 —el índice de precios del mercado pasó en este mismo período de un nivel de 108.6 puntos a 2155 puntos- Al igual que en otras economías emergentes, este auge se debió en gran parte a efectos inducidos por las privatizaciones de empresas públicas y las fuertes entradas de capitales asociadas a este proceso. Sin embargo, la crisis asiática y sus secuelas detuvieron el proceso e inauguraron una prolongada postración del mercado: en la segunda mitad de 2003, la recuperación de la economía peruana ya estaba bien asentada, y la bolsa de Lima recuperó niveles superiores a los alcanzados a mediados de 1997 (gráfica 8).

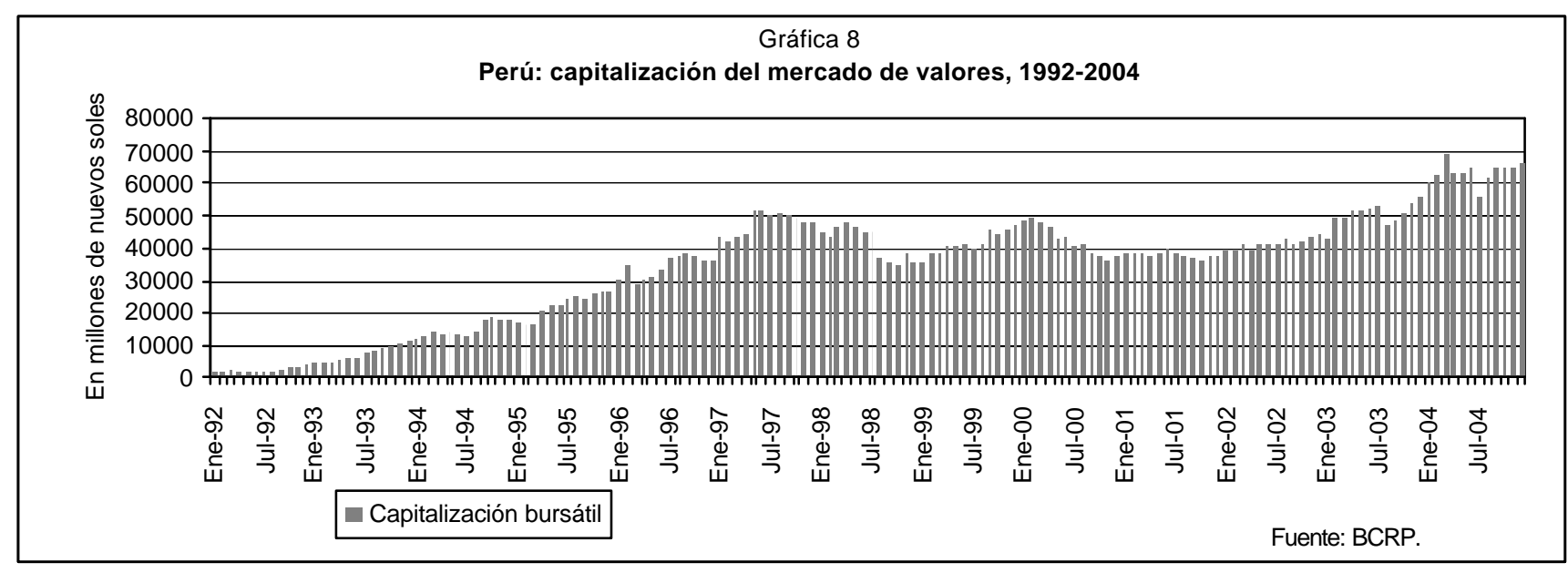


En contraste, el desarrollo de los mercados de bonos ha sido más tardío pero constituye en la actualidad una fuente de financiamiento más interesante para las corporaciones locales. Casi inexistente durante la primera mitad de los noventa, el mercado de bonos privados creció poco a poco después, reforzándose recientemente este proceso. En cuanto al mercado de bonos públicos, no existía antes de 1998. Si las primeras emisiones se realizaron con la finalidad de financiar el apoyo brindado al sistema bancario (1998-1999), a partir de 2002 se debieron a una política deliberada de las autoridades, que forma parte del esfuerzo por desarrollar el financiamiento en moneda nacional, al establecer una curva de rendimientos de referencia para el mercado de bonos privados en soles. De hecho, los últimos informes de las autoridades peruanas atribuyen parte del mayor dinamismo de este mercado al efecto positivo de esta política. Por el lado de la demanda, cabe subrayar el papel destacado desempeñado por las AFP, que absorben una gran parte de las emisiones de bonos públicos y privados.

En esta breve presentación se ha visto que las reformas financieras aunadas a la estabilización macroeconómica han permitido el resurgimiento y la diversificación del sistema financiero peruano. Sobre esta base, ¿es posible afirmar que este sistema se ha convertido en una fuerza que empuja el crecimiento del país? En la última sección de este trabajo revisaremos algunas características que muestran los límites y riesgos asociados a este sistema.

\section{Limitaciones y riesgos}

Destacaremos en esta última sección dos tipos de riesgos o limitaciones que afectan al sistema financiero peruano. En primer lugar, se analizará la problemática de la dolarización y de los riesgos que entraña; en segundo lugar, se discutirán el costo del crédito y de la segmentación del mercado.

A partir de 1997, las consecuencias de las crisis financieras internacionales en Perú pusieron de relieve los riesgos inherentes a un sistema financiero parcialmente dolarizado. Un primer riesgo surge de los movimientos bruscos en el tipo de cambio debido a que la mayoría de los deudores en divisas no recibe sin embargo ingresos en la misma moneda. Así, aún cuando los bancos no estén expuestos directamente al riesgo cambiario, pues por ley les está prohibido mantener desequilibrios entre la composición en divisas de sus pasivos y la de sus activos, sí lo están gran parte de sus acreditados.

Se estima que aproximadamente la mitad de la cartera de créditos comerciales del sistema bancario están concedidos a sectores

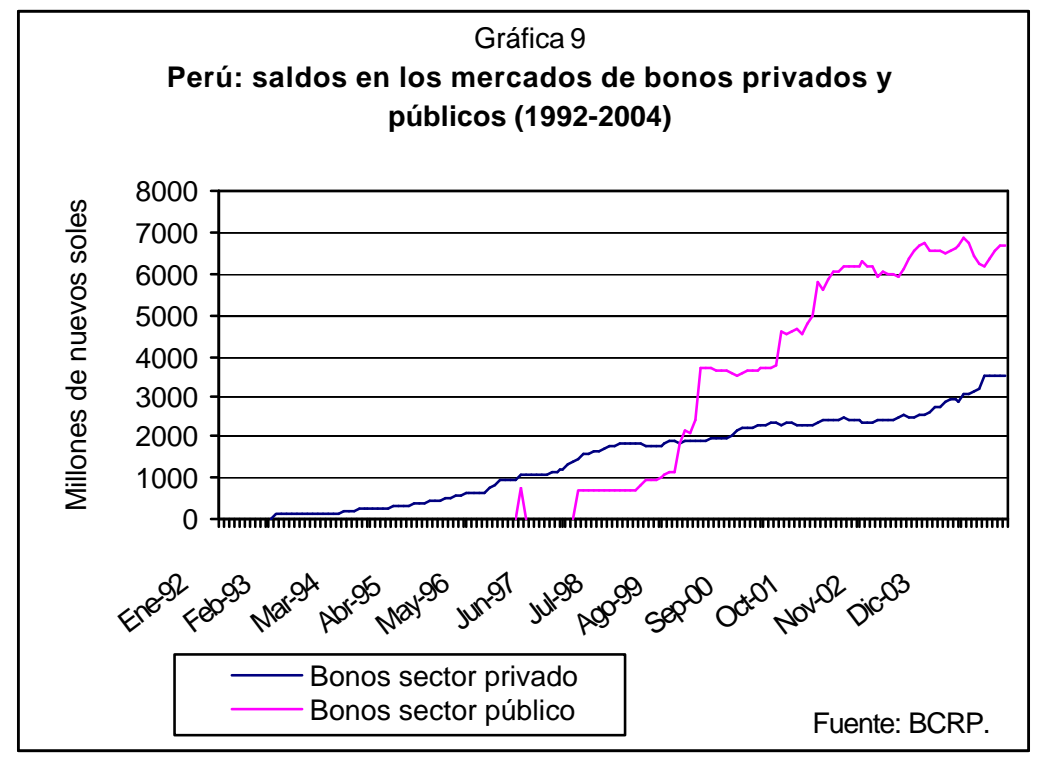


que no generan ingresos en divisas, como la construcción, el comercio y los servicios internos, la industria manufacturera que compite con importaciones. ${ }^{15}$ En estas circunstancias, una depreciación brusca de la moneda nacional eleva el valor de los pasivos en dólares de estos deudores en relación con el de sus activos denominados en soles, dificultándoles el cumplimiento de sus obligaciones financieras, y deteriorando la calidad de la cartera de crédito del sistema bancario. En breve, "el riesgo cambiario regresa a los bancos bajo la forma de créditos de mala calidad". ${ }^{16}$

Un segundo riesgo asociado a un sistema bancario semidolarizado proviene de las posibles “corridas" de depósitos en dólares, en caso de alguna acción que genere desconfianza entre los depositantes. Esto ha llevado a las autoridades peruanas a establecer dos líneas de defensa del sistema: el establecimiento de ratios de liquidez más elevados para los depósitos en moneda extranjera (20\%) y elevadas reservas internacionales, para que el banco central pueda cumplir con su papel de prestamista de última instancia del sistema bancario nacional y a la vez garantizar el cumplimiento de los compromisos de pagos externos.

Con esta finalidad, en 2002, Perú era el país de América Latina que tenía las reservas internacionales netas/liquidez del sistema bancario y las reservas internacionales netas/obligaciones externas de corto plazo más elevadas (respectivamente $65 \%$ y $44 \%$; cuando en Chile estas reservas alcanzaban niveles de $55 \%$ y $39 \%$, y en el caso de México, de $39 \%$ y $29 \%$ ). ${ }^{17}$ Ahora bien, en el caso extremo de una doble crisis, que combine una pérdida de confianza interna de los depositantes y un cierre de las fuentes externas de crédito, aún estas reservas podrían ser insuficientes en el corto plazo.

Cabe también tomar en consideración los elevados costos de oportunidad que implica mantener reservas internacionales y razones de liquidez tan elevadas: éstos son fondos que se encuentran desviados de su función de financiamiento del desarrollo económico. Por este conjunto de razones, y aún cuando las autoridades han minimizado la probabilidad de una especulación contra el sol peruano, en razón del carácter reducido de la liquidez en moneda nacional, tomaron, como lo hemos visto en la sección anterior, una serie de medidas destinadas a revertir paulatinamente la dolarización de la economía.

La segunda limitación del sistema financiero peruano, mencionada en un estudio reciente del FMI, tiene que ver con el elevado costo y el carácter inadecuado del financiamiento bancario recibido por una mayoría de empresas peruanas. Desde la liberalización de inicios de los noventa, las tasas de interés promedio tanto en soles como en dólares han disminuido notablemente, pero siguen siendo elevadas (gráficas 10 y 11). Así, en una economía que conoce desde varios años nive-

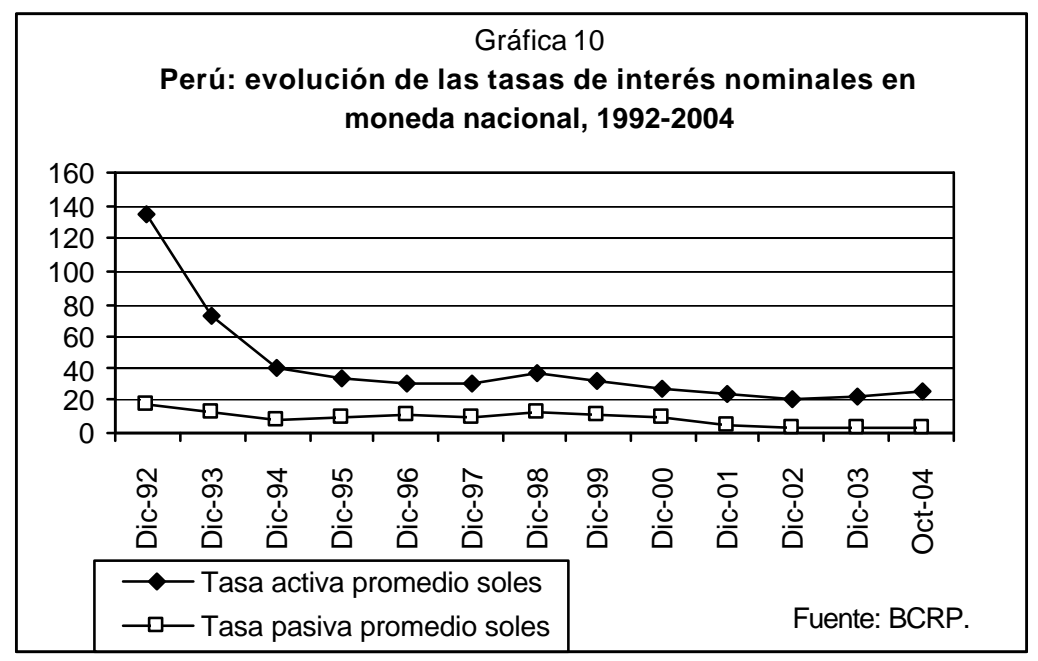


les de inflación bajos (alzas anuales del IPC inferiores a $2.5 \%$ desde 2001), las tasas nominales en soles seguían siendo mayores a $20 \%$, mientras las tasas en dólares apenas bajaban de $10 \%$.

Estas tasas promedio esconden, sin embargo, enormes diferencias entre los diversos tipos de solicitantes de crédito. Las diferencias son tales que se puede hablar de un mercado "segmentado" y heterogéneo, siguiendo el análisis realizado por el propio BCRP. El estudio distingue hasta seis submercados diferentes: empresas corporativas, mediana empresa, pequeña empresa, consumo, microempresa y mercado hipotecario, donde las condiciones y la disponibilidad de crédito varían ampliamente. ${ }^{18}$

El cuadro 4 muestra la amplia dispersión de las tasas de interés tanto en moneda nacional como en dólares; en soles las tasas iban en 2002 desde mínimos de $3.3 \%$ para las empresas corporativas mejor calificadas, hasta un máximo de $99 \%$ para la microempresa. Se observa a la vez que las corporaciones, que sumaban 200 empresas, concentraban $42 \%$ de los créditos concedidos a la vez que recibían condiciones mucho mejores, debido a que este segmento de clientes es el más competido y puede recurrir también al financiamiento vía la emisión de títulos negociables. ${ }^{19}$

Por el contrario, las empresas pequeñas y las microempresas tenían mayores dificul- tades para acceder al financiamiento, y éste les resultaba bastante caro. También es evidente si se consideran las elevadísimas razones de liquidez de los bancos, que éstos tienen la capacidad de prestar más; si no lo hacen, es probablemente por razones que tienen que ver tanto con la oferta como con la demanda.

Por el lado de la oferta, si excluimos las corporaciones, empresas medianas y las clases alta/media, los demás solicitantes de crédito carecen en general de las garantías adecuadas. Para prestarles sin riesgo excesivo, los bancos deben adoptar tecnologías diferentes, adaptadas a este tipo de clientes potenciales. Por el lado de la demanda, el costo elevado del crédito para la mayoría de los acreditados potenciales desincentiva claramente su acceso al crédito. En síntesis, el costo diferencial del crédito juega en Perú un papel que profundiza aún más las desigualdades y desfavorece la inversión de las capas menos pudientes.

Cabe mencionar que el informe citado preconizaba una serie de medidas para corregir estos defectos, y algunas de ellas ya fueron aplicadas recientemente: se trata en particular de medidas de difusión de la información relativa al costo del crédito y a las comisiones cobradas por los bancos, que permiten a los clientes de estas instituciones elegir mejor los servicios que adquieren. Los resultados de estas medidas fueron considerados positivos por las autoridades y éstas les

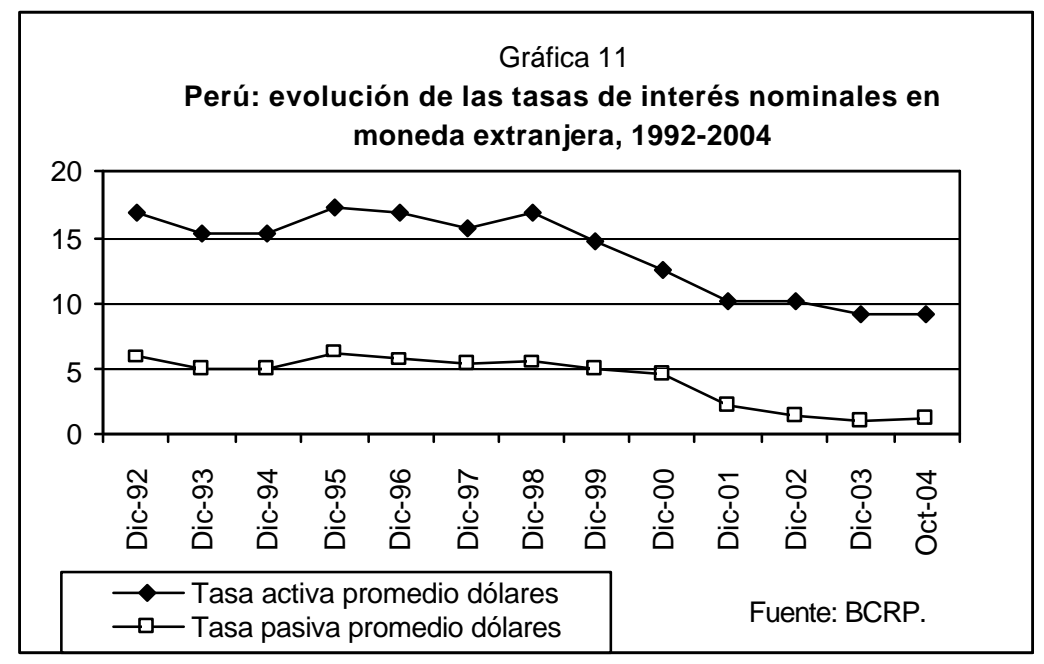


atribuyen parte de la disminución de las tasas de interés observada en los últimos años.

\section{Conclusión}

Este texto ha presentado la evolución del sistema financiero de Perú, haciendo hincapié en las últimas tres décadas. Ciertamente, las reformas liberalizadoras han permitido la reconstrucción del sistema y la profundización financiera después de la hiperinflación. Si bien implica riesgos y costos específicos, la parcial dolarización del sistema fue necesaria para alcanzar estos resultados y es sólo de manera muy reciente que la proporción de operaciones en soles ha ido elevándose.

El ahorro forzoso, producto del sistema de pensiones privado, ha permitido dinamizar el mercado de capitales, tradicionalmente muy poco desarrollado en Perú, fomentando cierta diversificación. Al otro extremo del sistema, la creación de una serie de instituciones de microfinanzas ha logrado incorporar al proceso formal de ahorro-inversión una franja creciente de la población peruana que no era sujeto de crédito bancario.

Por último, si bien esta evolución del sistema no ha estado exenta de sobresaltos, el manejo conservador y la intervención de las autoridades de supervisión han logrado evitar una crisis bancaria sistémica como producto de las crisis financieras externas y de la desaceleración de la economía peruana. La impresión general que se desprende del estudio del sistema financiero peruano es la de un crecimiento y una diversificación moderados desde 1990; por cierto muy bienvenidos después del agudo proceso de desintermediación sufrido en los ochenta pero que falta todavía dinamizarlo más y estimular la competencia de diferentes formas de financiamiento para mejorar el impacto del sistema sobre el crecimiento económico.

\section{Notas}

1 El marco general de la trayectoria macroeconómica de Perú se anliza ampliamente en Marchini, Geneviève, "Perú: del estancamiento económico a la reformulación del modelo de desarrollo (1975-2004)", en este mismo número de la revista México y la Cuenca del Pacífico.

2 Thorp, Rosemary y Geoffrey Bertram, Peru 1890-1977: Growth and Policy in an Open Economy, Macmillan Press Ltd, 1978, disponible en español con el título Perú 1890-1977: crecimiento y políticas en una economía abierta, Mosca Azul Ed., Fundación Friedrich Ebert y Universidad del Pacífico, Lima, 1985. Referencia en la p. 409 de la edición en español.

3 Marchini, Geneviève,"Un modelo macroeconómico de intermediación bancaria aplicado al caso del Perú, 19801990", ponencia presentada en el XI Encuentro Latinoamericano de la Sociedad Econométrica, 1992, El Colegio de México, México.

4 Los bancos Surmebanc, Banco de los Andes, Banco Amazónico y Banco Nor Perú fueron absorbidos en 1992 por el Banco Continental; mientras el Banco Sur del Perú fue absorbido en 1996 por Banco del Libertador para formar una entidad denominada Bancosur. Ledesma Liébana, Patricia, "The Peruvian Experience with Financial Liberalization", ponencia presentada en

Cuadro 4

Perú: dispersión de tasas de interés activas por segmentos (2002)

\begin{tabular}{lcccccc}
\hline Créditos en soles & Corporativo & $\begin{array}{c}\text { Mediana } \\
\text { empresa }\end{array}$ & $\begin{array}{c}\text { Pequeña } \\
\text { empresa }\end{array}$ & $\begin{array}{c}\text { Consumo } \\
\text { alto/medio }\end{array}$ & Microempresa & Hipotecario \\
\hline Promedio & 7.8 & 14.9 & 29.6 & 36.4 & 58.6 & 17.6 \\
Mínimo & 3.3 & 5 & 12.5 & 15 & 37 & 8.4 \\
$\quad$ Máximo & 14.5 & 30 & 39 & 46.8 & 99 & 26.8 \\
Créditos en dólares & & & & & & \\
$\quad$ Promedio & 6.5 & 9.6 & 13.5 & 16.4 & - & 12.6 \\
Mínimo & 2.5 & 4 & 10 & 12 & - & 11 \\
Máximo & 10 & 21 & 21 & 22 & - & 13.6 \\
Estructura de la cartera (en $\%$ del total de créditos) & & & \\
Créditos en soles & 12.1 & 3.8 & 1.6 & 4 & 3.7 & 0.3 \\
Créditos en dólares & 30 & 22.1 & 4.7 & 3.7 & 1.6 & 12.4 \\
Total & 42.1 & 25.9 & 6.3 & 7.7 & 5.3 & 12.7 \\
\hline
\end{tabular}

Fuente: BCRP, El costo del crédito en el Perú, pp. 60, 68 y 69. 
el Congreso de la Latin American Studies Association, Washington DC, septiembre de 2001, cuadro 5.

5 En abril de 1995, el Banco Continental fue vendido al Banco Bilbao Vizcaya en joint venture con el grupo peruano Brescia. En septiembre de 1995, Banco Santander adquirió el Banco Interandino, y en octubre del mismo año absorbió, a través de esta nueva adquisición, el Banco Mercantil, ibid.

6 Los grupos chilenos Osorno, Luksic y Errázuriz participaron respectivamente en la compra de los bancos Interbank, Banco del Libertador y Banco República, en julio de 1994 y mayo de 1995, ibid.

7 El banco Sudameris adquirió el Banco de Lima en septiembre de 1995, ibid.

8 Ibid., cuadro 6.

9 Orezzoli, Luis y Manuel Macera, "Intermediación financiera y concentración industrial. Efectos de la consolidación bancaria en el sector real de la economía", Economía y Sociedad, núm. 55, CIED, consultado en http:/ /consorcio.org/CIES/html/pdfs/Bol55/08orezzoli.pdf.

10 Ledesma Liébana, Patricia, "The Peruvian Experience with Financial Liberalization”, op. cit.
11 Superintendencia de Banca y Seguros, Memoria Anual 2003, p.11, http://www.sbs.gob.pe/Publica/memoria2003/memoria2003.pdf.

12 Superintendencia de Banca y Seguros, Las nuevas fortalezas del Perú, 2004, p. 21, http://www.sbs.gob.pe.

13 Ibid., pp. 18-20.

14 Ibid., p. 13 y Superintendencia de Banca y Seguros, Memoria Anual 2003, op. cit., p. 12.

15 FMI, "Perú: Selected Issues", ImF Country Report $n^{\circ} 04$ / 156, Washington DC, mayo de 2004, p. 26.

16 Ibid., p. 25.

17 Banco Central de Reserva del Perú,Protección de la economía de las vulnerabilidades creadas por la dolarización, Nota de difusión, 2003, http://bcrp.gob,pe/ Espanol/WPublicaciones/informes_especiales/ D0062003.pdf.

18 вCRP, El costo del crédito en el Perú, 2002, http:// b c r p.gob,pe/Espanol/W Publicaciones/ informes_especiales/D0172002.pdf.

19 Ibid., p. 3.

Para consultar otros números de la revistaM éxico y la Cuenca del Pacífico, ingresara la página de Internet: http://publicaciones.cucsh.udg.mx/pperiod/pacifico/index.html 